\title{
GÜNEY MARMARA BÖLGESI'NDE ARICILIK ANKET ÇALIŞMASI
}

\author{
A Study of Beekeeping Survey in Southern Marmara Region of Turkey \\ (Extended Abstract in English Can be Found at the End of the Article)
}

\begin{abstract}
A.Ebru BORUM
Balıkesir Üniversitesi, Veteriner Fakültesi, Mikrobiyoloji Anabilim Dalı, Balıkesir

ebruborum@balikesir.edu.tr

Geliş Tarihi: 04.04.2017 Kabul Tarihi: 16.05.2017

Öz

Bu çalışma Güney Marmara Bölgesi'nde Yalova, Bilecik, Bursa, Balıkesir ve Çanakkale'deki arıcıların genel özelliklerini belirlemek için yapılmıştır. Seksen arıcıya anket soruları yöneltilmiştir. Çalışmada arıcıların elde ettiği ürünler, kaç yıldır arıcılık yaptıkları, eğitim düzeyleri, yaş, hastalıkları tanıma, antibiyotik kullanma bilgileri gibi sorular yöneltilmiştir. Arıcılara 16 soru sorulmuştur. Arıcıların $\% 71,25$ 'inin 40 yaş ve üzeri olduğu, \%11,25'inin üniversite öğrenimine sahip olduğu, \%41,25'inin 10 yıl üzeri arıcılık yaptığı,\%83,75'inin ek iş ve hobi olarak yapıldığı, 100 ve üzeri kovan sayısına sahip olanların \%23,75 olduğu belirlenmiştir. Ayrıca \%83,75'inin birlik ve dernek üyesi olduğu, \%100'ünün bal üretimi yaptığı, \%69'unun ana arıyı ticari üreticiden aldığı,\%88,75'inin bal pazarlamasını kendi yaptığı, arıcıların \%100'ü varroa'yı, \%90'ı yavru çürüklüklerini, \%95'i kireç hastalığını, \%15'i taş hastalığını tanıyabildiklerini belirtmişlerdir. Arıcıların \%100'ü varroa, \%77,5'i yavru çürüklüğü, $\% 83,75$ 'i kireç hastalığı, \%2,5 taş hastalığına sıklıkla rastladıklarını belirtmişlerdir. Arıcılar kayıplarının $\% 80^{\prime}$ inin hastalıklar, $\% 12,5^{\prime}$ inin zirai ilaç ve $\% 7,5^{\prime}$ inin açlıktan kaynaklandığını belirtmişlerdir. Elde edilen verilere göre Güney Marmara Bölgesi arıcılığının genel özellikleri belirlenmeye çalışıımıştır.
\end{abstract}

Anahtar Kelimeler: Anket, Arıcı, Güney Marmara Bölgesi

\begin{abstract}
This study was conducted to determine the general characteristics of beekeepers in Yalova, Bilecik, Bursa and Balıkesir district of Southern Marmara Region. Questions were asked to 80 beekepeers. In the study, questions such as the products obtained by the beekeepers, how many years they have been beeing, education levels, age, diagnosis of diseases, information about antibiotics using have been asked. Sixteen questions have been asked. It was found that $71,25 \%$ of the beekeepers were over 40 years old, $11,25 \%$ had university education, $41,25 \%$ had beekeeping over 10 years, $83,75 \%$ were made as additional work and hobbies, $100 \%$ and $23,75 \%$. In addition, $83,75 \%$ are union and association members, $100 \%$ are honey producers, $69 \%$ are main producers from commercial producers, $88,75 \%$ own honey marketing, $100 \%$ of beekeepers are Varroa, $90 \%$ Of them were able to recognize rot fungi, $95 \%$ of chalkbrood, and $15 \%$ of stonebrood. They stated that $100 \%$ of the beekeepers were found in varroa, $77,5 \%$ of them were foulbrood, $83,75 \%$ were found to have chalkbrood and $2,5 \%$ stonebrood. Investigators have reported that $80 \%$ of the losses are caused by diseases, $12,5 \%$ by pesticides and $7,5 \%$ by hunger. According to the obtained data, the general characteristics of the Southern Marmara Region beekeeping were tried to determine.
\end{abstract}

Key words: Survey, Beekeeper, Southern Marmara Region 


\section{ARAŞTIRMA MAKALESI / RESEARCH ARTICLE}

\section{GíRiş}

Türkiye dünyadaki arı ırklarının \%20'sini barındırmaktadır. Arı yetiştiriciliği ve bal üretiminde temel etken olan coğrafyanın, iklim şartları ve ballı bitki florasının uygun olmasıdır. Dünyada mevcut olan ballı bitki tür ve çeşitlerinin \%75'inin Türkiye'de bulunması büyük bir doğal zenginliktir. Zengin florası, uygun ekolojisi, koloni varlığı ve arı popülasyonlarında ki genetik varyasyon bakımından Türkiye büyük bir arıcılık potansiyeline sahiptir. Bütün bu olumlu koşullara rağmen bal üretimimiz ve ihracatımız istenilen düzeyde olmamaktadır. Bunun en önemli nedenlerinden birisi arı hastalık ve zararlıları hakkında yeterli ve doğru bilgiye sahip olunmaması, hastalık için gerekli mücadelenin, koruma ve kontrolün zamanında ve doğru bir şekilde yapılmamasıdır. Ayrıca hastalıkların teşhisinde yapılan hatalar ve bilinçsiz ilaç kullanımları da oldukça önemlidir. Gereksiz ve yanlış ilaç kullanımları hem arı hem de insan sağlığını ciddi anlamda tehdit etmektedir (Tutkun ve Boşgelmez., 2003).

Marmara bölgesi koloni sayısı bakımından 7.verim bakımından ise 2. sıradadır (Çakmak ve ark., 2003). Arıcılık pek çok arıcı tarafından esas geçim kaynağı olabildiği gibi, diğer tarımsal faaliyetlerin ya da mesleklerin yanı sıra ikinci bir gelir kaynağı olarak da yapılabilmektedir. Az sermaye gereksinimi yanında arazi, tesis, alet-makine ve fazla işgücü gerektirmemesi bu üretim dalının avantajları arasında sayılmaktadır. Ayrıca arı yetiştiriciliğinde sermaye başta olmak üzere gerekli bütün ekipman ve canlı materyalin Türkiye içerisinden karşılanması da diğer bir avantajdır (Üçeş ve Erişir, 2016).

Türkiye'de arıcılık sektöründeki sorunların belirlenip gerekli tedbirlerin alınması durumunda, arıcılığımız dünyadaki gerçek yerini alacaktır. Bunun için de, bölgesel ve yerel düzeyde arıcılarımızın ve arıcılık faaliyetlerimizin yeterince tanınmasıdır. Bunu sağlayabilmek için anket çalışmaları yapılarak sorunlar saptanmalı, sorunların çözümü için yol haritası belirlenmelidir.

Ülkemizde arıcılık ile ilgili yapılan birtakım anket çalışmaları mevcuttur. Bu çalışmaların daha da çoğaltılarak sorunların çözümlerinin belirlenmesi hem bölgesel durumu göstermesi hem de sonuca ulaşmayı sağlamada oldukça önemlidir.

\section{GEREÇ VE YÖNTEM}

Bu çalışmada Güney Marmara Bölgesinde arıcılığın ve arıcıların genel özelliklerini belirlemek için 80 arıcı ile anket çalışması yapılmıştır. Güney Marmara Bölgesinde Bursa, Bilecik, Çanakkale, Yalova ve Balıkesir illerindeki arıcılar ile anket çalışması yapılmıştır. Anket formunda; yaş, meslek, kaç yıllık arıcı olduğu, öğrenim durumu, elde ettiği ürünler, ne tür arıcılık yaptığı, kovan sayısı, bilgi ve çözüm için kimden yararlandığı, hastalıkları tanıyıp tanımadığı, ana arı değişimi ve üretimi yapıp yapmadığı, en sık rastlanan hastalıklar, antibiyotik kullanımı, pazarlama, kayıplar, dernek, birlik üyelikleri konusunda 16 soru yöneltilmiştir. Anket yapılan arıcılara ankete kesin ve net cevaplara verilmesi bu cevapların herhangi bir sorumluluk yüklemeyeceği konusunda bilgi verilmiştir. Ayrıca bu arıcıların kovan kontrolleri de yapılmıştır.

\section{BULGULAR}

Bu çalışmada 80 arıcıya 16 soru sorulmuştur.

1- Kaç yaşındasınız?

20-40: 23 (\%28,75)

40 ve üzeri: $57(\% 71,25)$

Arıcıların $\% 28,75$ 'i $20-40$ yaş arası, $\% 71,25$ 'inin ise 40 yaş üzeri olduğu belirlenmiştir.

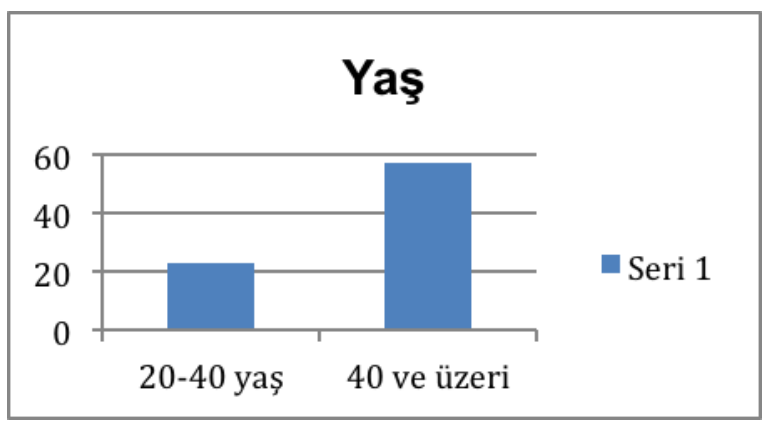

2- Öğrenim Durumu:

İlkokul: $27(\% 33,75)$

Ortaokul: $23(\% 28,75)$

Lise: $21(\% 26,25)$

Üniversite: $9(\% 11,25)$

Arıcıların \%33,75'inin ilkokul, \%28,75'inin ortaokul, $\% 26,25$ 'inin lise, $\% 11,25$ 'inin ise üniversite öğrenimine sahip olduğu öğrenilmiştir. 


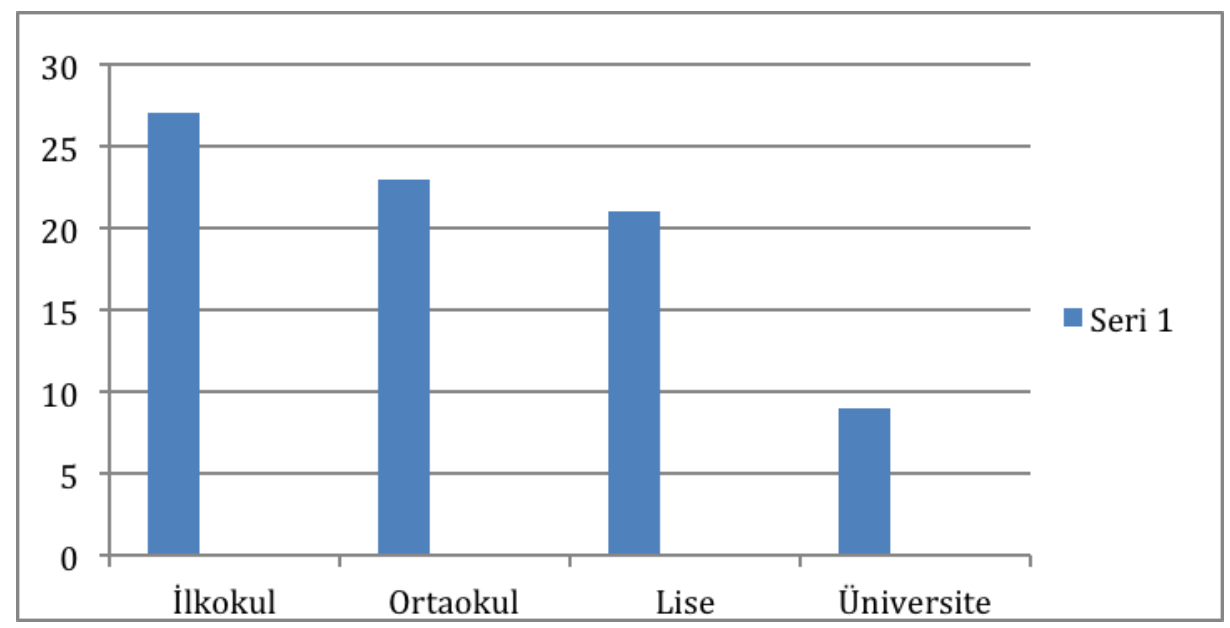

3- Kaç yıldır arıcılık yapıyorsunuz?

0-5 yıl: $22(\% 27,5)$

5-10 yıl: $25(\% 31,25)$

10 yıl ve üzeri: $33(\% 41,25)$

Araştırmaya göre \%27,5'inin 0-5 yıl, \%31,25'inin 5$10 \mathrm{yıl}, \% 41,25$ 'inin ise $10 \mathrm{yıl}$ ve üzeri arıcılık yaptığı belirlenmiştir.

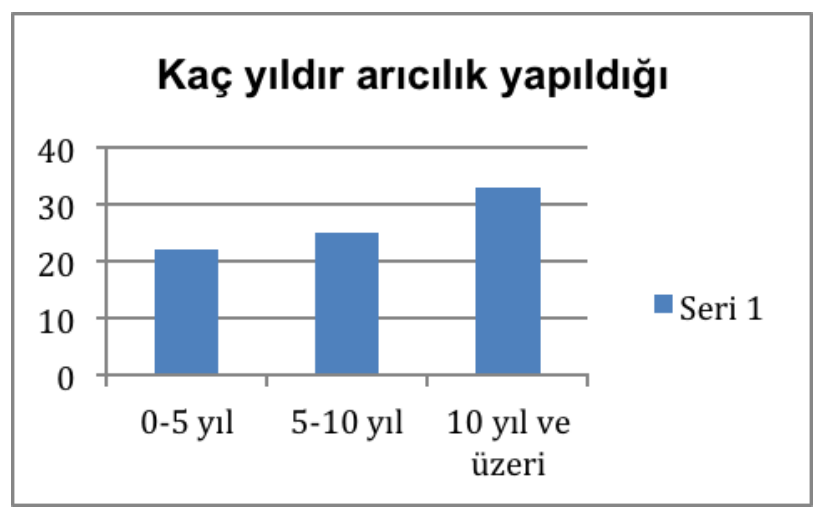

4-Arıcıların bu işi asıl meslek olarak mı, ikinci gelir ve hobi olarak mı yaptıkları:

Asıl: $13(\% 6,25)$

Hobi-2. İş: $67(\% 83,75)$
Arıcıların \%6,25’i asıl meslek olarak, \%83,75’i ise ek gelir ve hobi olarak yaptıklarını söylemişlerdir.

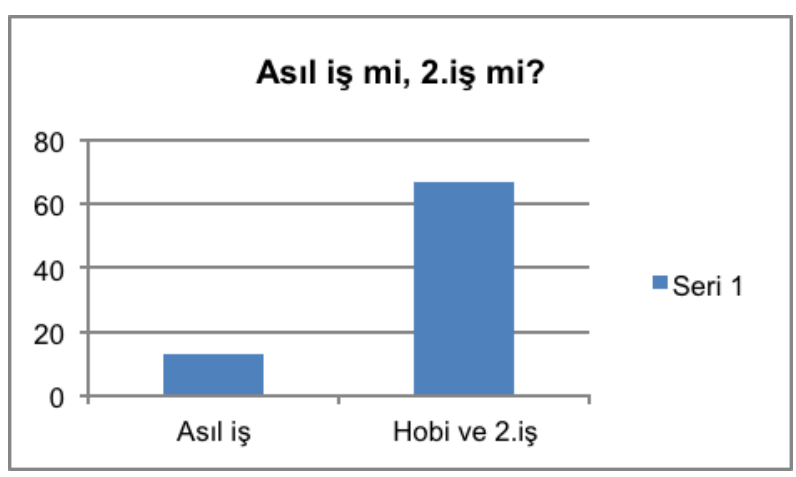

5-Kovan sayısı:

1-10: 32 (\%40)

10-50: $22(\% 27,5)$

50-100: $7(\% 8,75)$

100 ve üzeri: $19(\% 23,75)$

Kovan sayısı 1-10 arası olanlar \%40, 10-50 arası $\% 27,5,50-100$ arası $\% 8,75,100$ ve üzeri ise $\% 23,75$ olarak belirlenmiştir. 
ARAŞTIRMA MAKALESI / RESEARCH ARTICLE

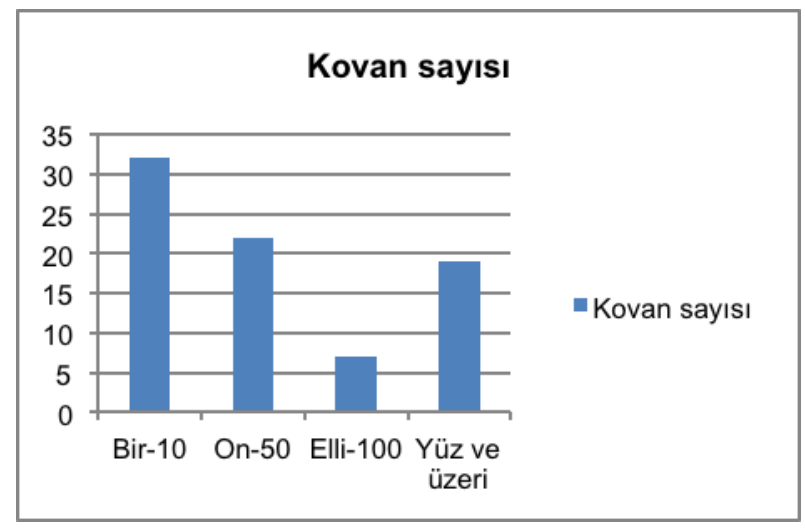

6-Sabit mi, gezgin mi arıcılık yapıldığı:

Sabit: $65(\% 81,25)$

Gezgin: $15(\% 18,75)$

Arıcıların \%81,25'i sabit, \%18,75’i gezgin arıcılık yaptığını bildirmiş̧lerdir.

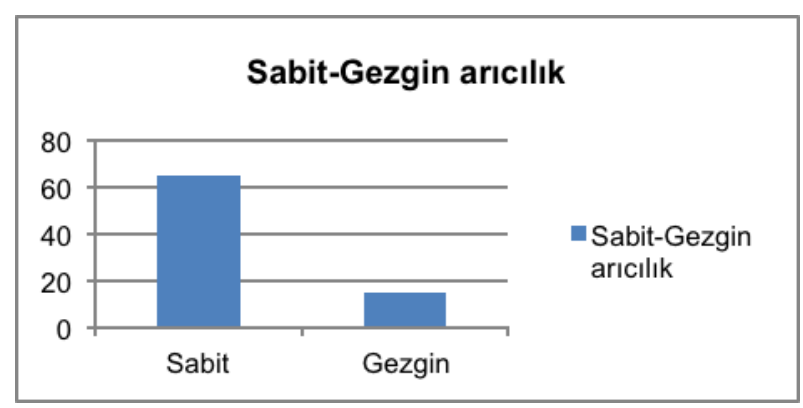

7-Hangi arı ürünü üretimi yaptığı:

Bal.80 (\%100)

Polen: $62(\% 77,5)$

Propolis: $25(\% 31,25)$

Arı sütü: 20 (\%25)

Arıcıların $\% 100$ 'ü bal, $\% 77,5^{\prime} \mathrm{i}$ polen, $\% 31,25^{\prime} \mathrm{i}$ propolis, $\% 25$ 'i arı sütü üretimi yaptığını belirtmişlerdir.

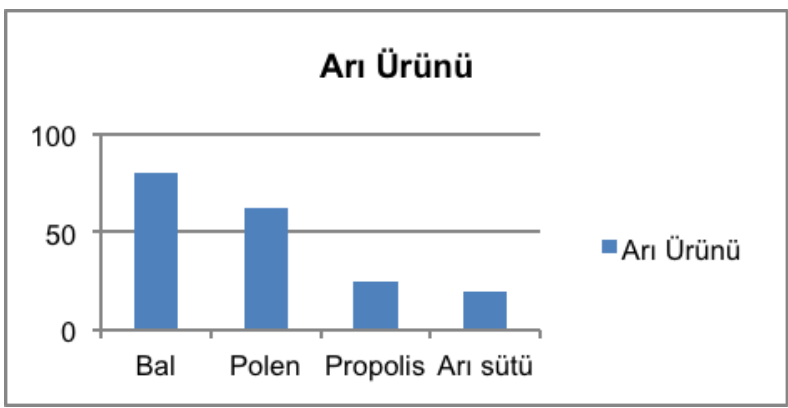

8-Dernek, Birlik üyeliği:

Üye: 67 (\%83.75)

Üye değil: 13 (\%16.25)

Arıcıların \%83.75'i bir arıcılık birlik veya derneğine üye iken \%16.25'inin üye olmadığı belirlenmiştir.

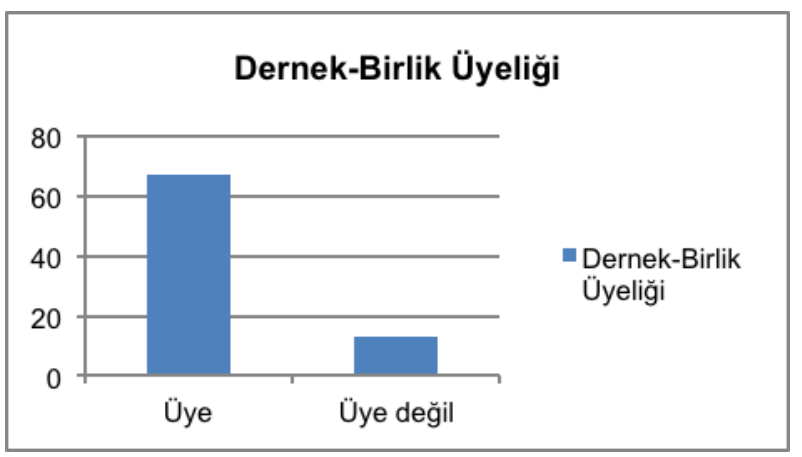

9-Bilgi alma ve sorun çözümü için kimlere başvurulduğu:

Deneyimli arıcılar: $48(\% 60)$

Arıcı birlik ve dernekleri: $22(\% 27,5)$

Üniversiteler: $10(\% 12,5)$

Arıcıların \%48'inin deneyimli arıcılardan, \%27,5'inin arıcı dernek ve birliklerinden, \%12,5'inin ise üniversitelerden bilgi ve sorun çözüm desteği aldıkları belirlenmiştir. 


\section{ARAŞTIRMA MAKALESI / RESEARCH ARTICLE}

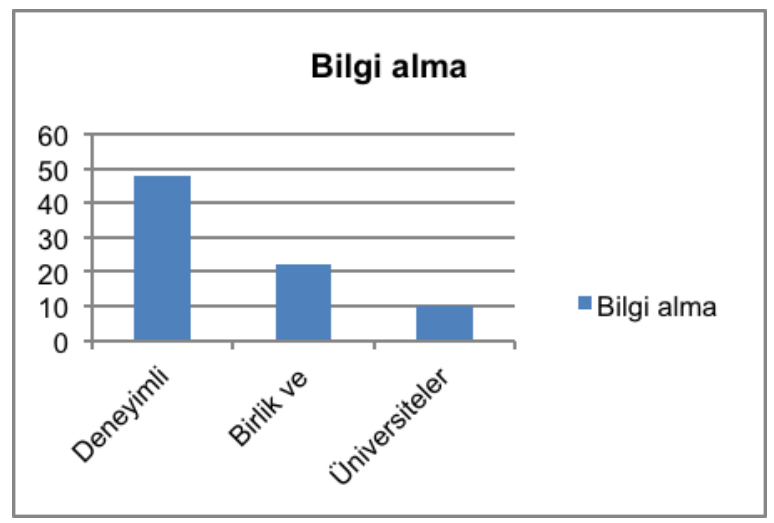

10-Ana arının nereden elde edildiği:

Ticari üretici: $69(\% 86,25)$

Kendi: $11(\% 13,75)$

Ana arıyı arıcıların \%86,25'i ticari üreticilerden, $\% 13,75^{\prime} i$ ise kendisi tarafından sağlandığını belirtmişlerdir.

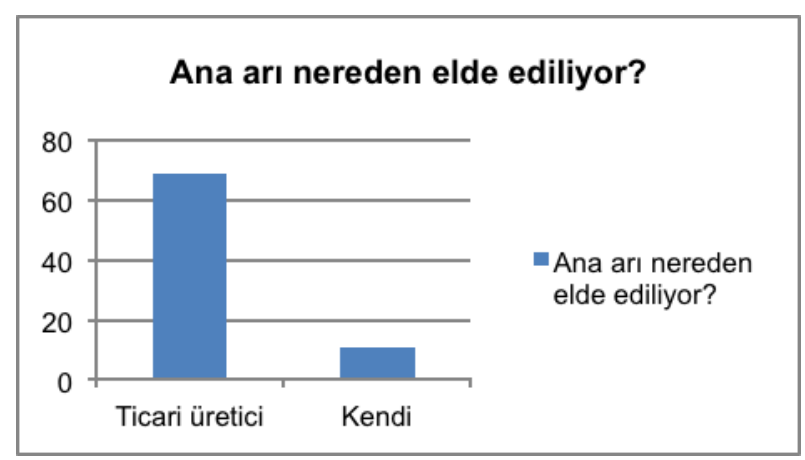

11-Ana arı değişiminin ne sıklıkta yapıldığı:

1 yıl: $5(\% 6,25)$

2 yıl: $30(\% 37,5)$

3 yıl: $15(\% 18,75)$

Değiştirmiyor: $30(\% 37,5)$

Arıcıların \%6,25'i 1 yıl, \%37,5'i 2 yıl, \%18,75'i 3 yıl ara ile değiştirdiğini, \%37,5'i ise değiştirmediğini belirtmişlerdir.

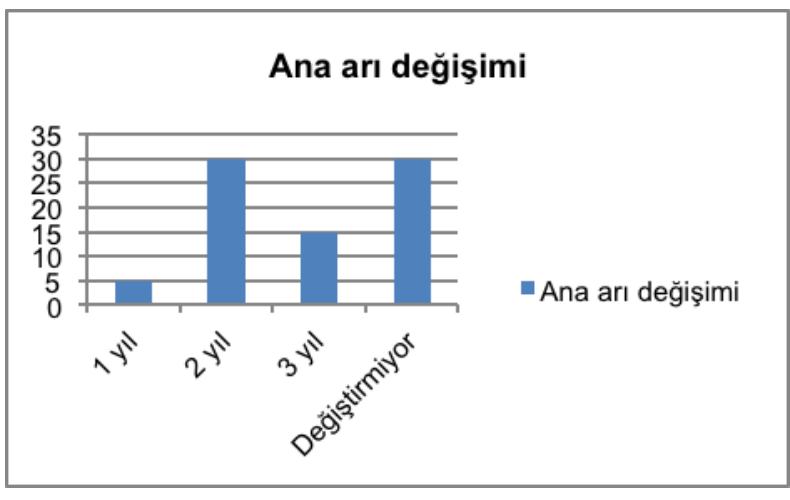

12-Bal pazarlaması:

Kendi: $71(\% 88,75)$

Toptan: $9(\% 11,25)$

Arıcıların \%88,75'i bal pazarlamasının kendileri tarafından yapıldığını, $\% 11,25^{\prime} i$ ise toptan verdiklerini belirtmişlerdir.

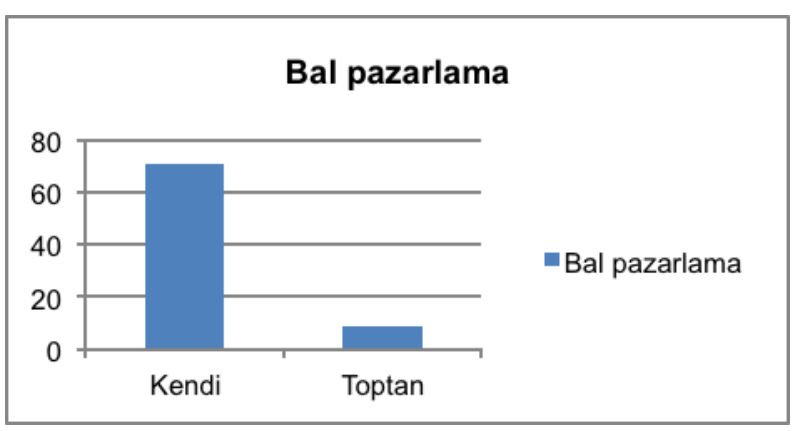

13-Arı Hastalıklarını Tanıma:

Varroa: 80 (\%100)

Yavru Çürüklüğü: 72 (\%90)

Kireç Hastalığı: 76 (\%95)

Taş Hastalığı: 12 (\%15)

Arıcıların \%100'ü varroa'yı, \%90'ı yavru çürüklüklerini, \%95'i kireç hastalığını, \%15'i taş hastalığını tanıyabildiklerini belirtmişlerdir. 


\section{ARAŞTIRMA MAKALESİ / RESEARCH ARTICLE}

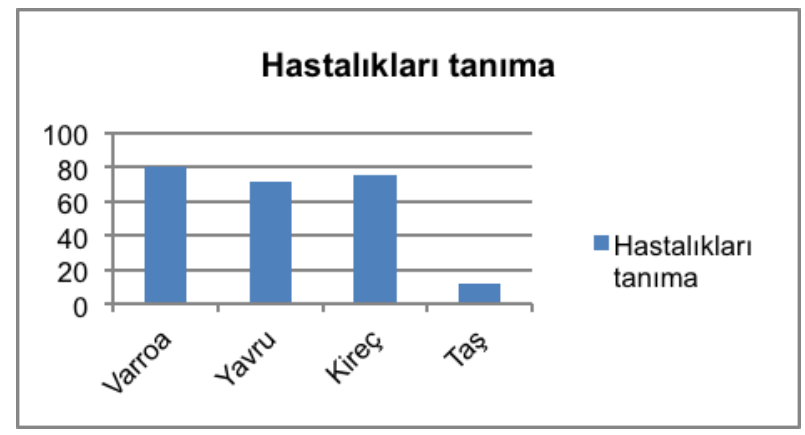

14-En sık rastlanan hastalıklar:

Varroa: 80 (\%100)

Yavru çürüklüğü: $62(\% 77,5)$

Kireç hastalığı: $67(83,75)$

Taş Hastalığı: $2(\% 2,5)$

Arıcıların \%100'ü varroa, \%77,5'i yavru çürüklüğü, $\% 83,75$ 'i kireç hastalığı, \%2,5 taş hastalığına sıklıkla rastladıklarını belirtmişlerdir.

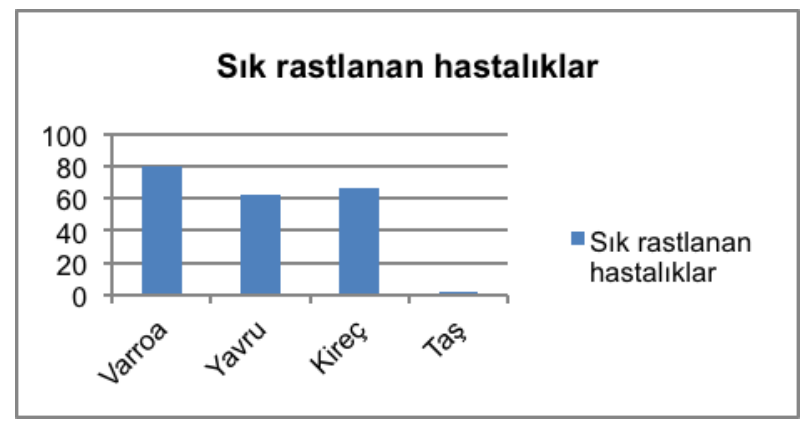

15-Kayıplar:

Hastalık: 64 (\%80)

Zirai ilaç: $10(\% 12,5)$

Açlık: $6(\% 7,5)$

Arıcılar kayıplarının \%80'inin hastalıklar, \%12,5'inin zirai ilaç ve \%7,5'inin açlıktan kaynaklandığını belirtmişlerdir.

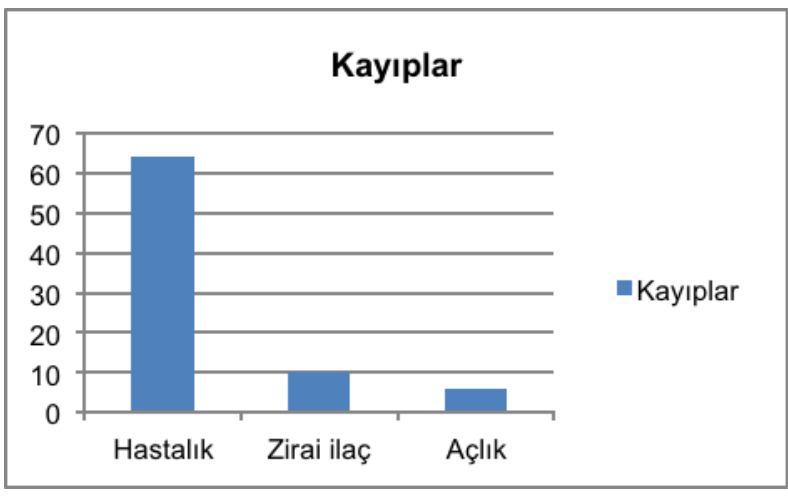

16-Antibiyotik kullanımı:

Kullanırım: 66(\%82,5)

Kullanmam: 14 (\%11,25)

Arıcıların \%82,5'i antibiyotik kullandığını, \%11,25'i ise kullanmadığını belirtmiştir.

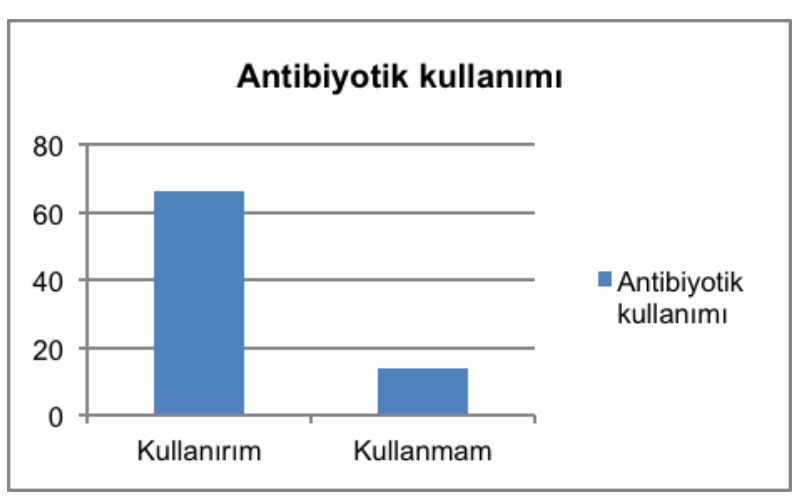

\section{TARTIŞMA}

Bizim çalışmamızda da 20-40 yaş arası arıcıların $\% 28,75^{\prime} \mathrm{i}, 40$ yaş ve üzeri arıcıların ise $\% 71,25$ ' $\mathrm{i}$ oluşturduğu belirlenmiştir. Yaş ilerledikçe arıcılık ile uğraş artmakta, genç ve çalışan nüfus ise ilgilenmeyi tercih etmemektedir. Erzincan'da yapılan bir çalışmada arıcıların yaş ortalaması $\% 30$ oranında 46-55 yaş olarak bulunmuştur (Üçeş ve Erişir, 2016). Diyarbakır'da yapılan bir çalışmada ise yaş ortalaması 46,38 olarak bulunmuştur (Demen, 2015). Hizan'da yapılan bir anket çalışmasında ise arıcılık faaliyeti ile ilgilenenlerin, \%42'sinin 41-50 yaş arası, \%28'inin 31-40 yaş 


\section{ARAŞTIRMA MAKALESI / RESEARCH ARTICLE}

arası, \%23'ünün ise 21-30 yaş aralığında olduğu belirlenmiştir (Kutlu ve ark., 2016).

Arıcılık ile uğraşanların \%33,75'inin ilkokul, $\% 28,75^{\prime}$ inin ortaokul, \%26,25'inin lise, \%11,25'inin ise üniversite öğrenimine sahip olduğu öğrenilmiştir. Yapılan bir çalışmada arıcılıkla uğraşanların \%43'lük kısmının ilkokul, \%26'lık kısmının ortaokul, \%18'lik kısmının lise ve \%13'lük kısmının ise üniversite öğrenimi olduğu bildirilmiştir (Üçeş ve Erişir, 2016). Edirne ilinde yapılan bir araştırmada ise arıcıların \%68,7'sinin ilkokul, \%9,4'ünün ortaokul, \%15,6'sının lise, \%6,3'ünün yüksekokul mezunu olduğu belirtillmiştir (Yılmaz, 1999). Hizan'da yapılan bir çalışmada arıcıların \%51' inin ortaokul, \%26'sının ilkokul, \%18'inin lise, \%5'inin üniversite mezunu olduğu görülmüştür (Kutlu ve ark., 2016). Tekirdağ ilinde yürütülen bir çalışmada, yetiştiricilerin \%13'ünün okur-yazar değil, \%50'sinin ilkokul, \%15'inin ortaokul, \%20'sinin lise, \%2'sinin ise üniversite mezunu olduğu belirlenmiştir (Soysal ve Gürcan, 2005). Eğitim seviyesi arttıkça arıcılık ile ilgilenme oranı düşmektedir.

Araştırmaya göre arıcıların \%27,5'inin 0-5 yıl, $\% 31,25$ 'inin 5-10 yıl, \%41,25'inin ise 10 yıl ve üzeri arıcılık yaptığı belirlenmiştir. Özbilgin ve ark., (1999)'nın Ege Bölgesinde yaptığı anket çalışmasında arıcılığın 18 yıl, Şahinler ve Gül (2003)'ün Hatay ilinde yaptığı çalışmasında ise ortalama 10,5 yı arıcılık deneyimleri olduğu belirlenmiştir.

Arıcıların \%6,25'i asıl meslek olarak, \%83,75'i ise ek gelir ve hobi olarak yaptıklarını söylemişlerdir. Erzincan'da yapılan bir çalışmada yan gelir olarak arıcılığı yapanlar \%60 olarak bulunmuştur (Üçeş ve Erişir, 2016). Ağrı, Kars, Iğdır ve Ardahan bölgesinde yapılan araştırmada ise arıcıların \%40'ının tek geçim kaynağının arıcılık olduğu belirlenmiştir (Sezgin ve Kara, 2011). Elde edilen sonuçlar arıcılığın daha çok ek gelir elde etmek amacıyla yapıldığını göstermektedir.

Kovan sayısı $1-10$ arası olanlar \%40, 10-50 arası $\% 27,5,50-100$ arası $\% 8,75,100$ ve üzeri ise $\% 23,75$ olarak belirlenmiştir. Aydın ve ark. (2003) tarafından yapılan ankete katılan arıcıların \%76'sının kovan sayısı 100'den az, \%16'sının 100 ile 200 arası, \%8'inin ise 200'den daha fazla olduğu belirlenmiştir. Bu da kovan sayısının genellikle 1050 arasında olduğunu göstermektedir. Ayrıca tecrübe arttıkça arıcılar kovan sayısı arttırma eğilimindedir.
Arıcıların \%81,25'i sabit, \%18,75’i gezgin arıcılık yaptığını bildirmişlerdir. Düzce'de yapılan bir çalışmada arıcıların\%79,5'inin sabit, \%21,5'inin ise sabit arıcılık yaptığı bildirilmiştir (Kekeçoğlu ve Rasgele, 2013).

Bu sonuçlar, arıcıların daha çok sabit arıcılığı tercih ettiğini göstermektedir. Bu da gezginci arıcılığın daha fazla vakit alması ve taşımak için araca ihtiyaç duyulmasından kaynaklanmaktadır. Gezginci arıcılar kovan başına daha fazla bal elde etmektedirler.

Arıcıların \%100'ü bal, $\% 77,5$ 'i polen, $\% 31,25$ 'i propolis, \%25'i arısütü üretimi yaptığını belirtmişlerdir. Hizan'da yapılan bir araştırmada, $100 \mathrm{arıcı}$ bal dışında propolis ve arı zehri üretmemekte, $\% 75$ oranında oğul arı, $\% 15$ oranında polen, $\% 7$ oranında ana arı ve $\% 3$ oranında arı sütü ürettiği bildirilmiştir (Kutlu ve ark. 2016).

Bal dışındaki polen, propolis, ana sütü gibi ürünlerin üretim oranları istenen düzeyde değildir. $\mathrm{Bu}$ nedenle arıcılığın tek ürünün bal olmadığı, diğer arı ürünlerinin de üretim kaynakları olduğu arıcılara fark ettirilmelidir. Bu amaca yönelik eğitimler, kurslar ve seminerler düzenlenerek arıcılar bilinçlendirilmelidir.

Arıcıların \%83,75'i bir arıcılık birlik veya derneğine üye iken \%16,25'inin üye olmadığı belirlenmiştir. Yığılcalı arıcılarda yapılan bir çalışmada arıcıların $\% 76,7$ 'si birliklere üye iken, sadece \%23,3'ünün herhangi bir birliğe üye olmadığı bildirilmiştir (Kekeçoğlu ve Rasgele, 2013).

Çakmak ve arkadaşları (2003) tarafından yapılan bir çalışmada arıcıların \%70'inin bir derneğe üye olduğu, \%30'unun ise üye olmadığı bildirilmiştir. Görüldüğü gibi arıcıların büyük çoğunluğu örgütlenebilmiştir. Bu da arıcılar arasında iletişim ve bilgi alışverişinin olmasını sağlamakta, ayrıca herhangi bir problem karşısında dernek ve birliklerden bilgi alabilmekte etkili olmaktadır.

Arıcıların \%48'inin deneyimli arıcılardan, \%27,5'inin arıcı dernek ve birliklerinden, \%12,5'inin ise üniversitelerden bilgi ve sorun çözüm desteği aldıkları belirlenmiştir. Hizan'da yapılan bir çalışmada sorunların çözümünde $\% 52$ oranında deneyimli arıcılara, \%32 oranında tarım teşkilatlarına, \%16 oranında ise arıcı birliklerine yöneldikleri kaydedilmiştir (Kutlu ve ark., 2016).

Görüldüğü üzere henüz üniversiteler ya da dernek ve birliklerden yardım almak yerine sorunların 


\section{ARAŞTIRMA MAKALESI / RESEARCH ARTICLE}

çözümü için daha deneyimli arıcılardan bilgi alınmaktadır. Ancak üniversitelere yönelmenin artırılması, bunun için üniversiteler ile arıcılar arasında iletişimi sağlamak, kurs, sertifika ve seminer programları düzenlemek yerinde olacaktır.

Anaarıyı arıcıların \%86.25’ ticari üreticilerden, $\% 13,75$ 'i ise kendisi tarafından sağlandığını belirtmişlerdir. Yığılca'da yapılan bir çalışmada \%8,2'si suni olarak ürettikleri ana arıyı kullandığı belirtilmiştir (Kekeçoğlu ve Rasgele, 2013).

Gaziantep'te yapılan bir çalışmada arıcıların ana arılarını Çukurova bölgesinde ana arı üretimi yapan işletmelerden satın alarak değiştirdiği, \%8'inin ana arı ihtiyaçlarını kendilerinin üreterek karşıladıkları, $\% 80$ 'i ise ana arı kullanmayıp kolonilerini oğulla veya doğal yolla bölme yaparak çoğalttıkları tespit edilmiştir (Kutlu, 2014).

Van Bahçesaray'da yapılan bir araştırmada, gezginci arıcıların \%73,33'ünün, sabit arıcıların ise $\% 76,09$ 'unun ana arıları kendi arılıklarından sağladıkları ortaya konmuştur (Erkan ve Aşkın, 2001). Ana arı üretimi için merkezler kurulabilir ya da arıcının kendi üretmesi teşvik edilebilir. Çünkü ana arı koloni sağlığının güvencesidir. Bilinmeyen ve sağlıklı olmayan ana arıların alınması ciddi hastalıkların kolonilere bulaşmasına ve koloni kayıplarına sebep olabilir.

Arıcıların \%6,25’i 1 yıl, \%37,5’i 2 yıl, \%18,75’i 3 yıl ara ile değiştirdiğini, \%37.5'i ise değiştirmediğini belirtmişlerdir. Yığılcalı arıcıların \%1,4'ü üç yılda bir, $\% 4,1$ 'i iki yılda bir ana arıyı değiştirmektedirler. $\% 8,2$ 'si suni olarak ürettikleri ana arıyı kullanmakta,\%91,8'i ise ana arıyı hiç değiştirmemekte, koloninin kendisi tarafından doğal olarak oluşturulan anaarıları kullandıkları bildirilmiştir (Kekeçoğlu ve Rasgele, 2013).

Güney Marmara bölgesinde yapılan bir anket çalışmasında kişilerin \%76'sının ana arılarını kendilerinin yetiştirip 2-3 yılda bir değiştirdiği bildirilmiştir (Çakmak ve ark., 2003). Van Bahçesaray'da yapılan bir anket çalışmasında gezginci arıcıların hepsi, sabit arıcıların ise $\% 54,12$ 'si kolonilerin ana arılarını kendileri değiştirirken \%45,88 oranında sabit arıcı kolonilerin ana arılarının değişmesini doğal süre içerisine bıraktığı tespit edilmiştir (Erkan ve Aşkın, 2001). Koloninin en önemli bireyi genetik özelliklerin kaynağı olması nedeniyle ana arıdır. Koloninin performansı, verimi, hastalıklara dayanıklıı̆ı kolonide bulunan ana arının genetik potansiyeline ve ana arının yaşına bağlıdır. Ortalama 4-5 yıllık ömüre sahip olan ana arı, yaşamının ancak ilk iki yılında en yüksek performansı ve verimi gösterebilir. Bu nedenle, başarılı ve kazançlı bir arıcılık için ana arıların her yıl ya da 2 yılda bir değiştirilmeleri gereklidir

Arıcıların \%88,75’i bal pazarlamasının, kendilerinin yaptığını, \%11,25'i ise toptan verdiklerini belirtmişlerdir. Yapılan bir anket çalışmasında gezginci arıcıların \%26,67'inin, sabit arıcıların ise \%88,23'ünün ballarını kendilerinin pazarladıkları bildirilmiştir. Ballarını aracılara verip pazarlayan arıcıların oranı gezginci arıcılarda \%73,33, sabit arıcılarda ise \%4,71 olarak hesaplanmıştır (Erkan ve Aşkın, 2001). Gezginci arıcılar daha fazla bal elde etmektedirler. Dolayısıyla satış konusunda zorlanmaktadırlar. Aracılara ya da toptancılara bal vermektedirler. $\mathrm{Bu}$ da arıcının aldığı kar payını düşürmekte ve daha az kazanmalarına neden olmaktadır. Sabit arıcılık yapanların çoğunluğu daha az bal elde ettiği için aracılar olmaksızın kendileri pazarladıklarından daha fazla kazanç elde etmektedirler.

Arıcıların \%100'ü varroa'yı, \%90'ı yavru çürüklüklerini, \%95’i kireç hastalığını, \%15’i taş hastalığını tanıyabildiklerini belirtmişlerdir. Van Bahçesaray'da yapılan bir ankette sabit arıcılar $\% 34,12$ oranında varroa ve yavru çürüklüğünü tanırken, gezginci arıcılar \%53,33 oranla dört hastalık varroa, yavru çürüklüğü, kireç ve ishali tanıdıkları bildirilmiştir. Bütün arı hastalık ve zararlılarını tanıdığını söyleyen arıcıların oranı gezginci arıcılarda \%26,66; sabit arıcılarda \%4,71 olarak hesaplanırken sabit arıcıların \%3,53'ü hiçbir hastalığı tanımadığını ifade etmiştir (Erkan ve Aşkın 2001). Yapılan bir araştırmada arıcıların, bal arısı zararlısı olan Varroa jacobsoniyi \%89, arı felcini $\% 2$ nosema'yı \%16, mum güvesini \%55, Avrupa ve Amerikan yavru çürüklüğünü (spesifik olarak değil de genel yavru çürüklüğü adı altında tanıdıkları) $\% 24$, kireç hastalığını ise \%13 oranında tanıdıkları belirlenmiştir (Kutlu, 2014).

Hizan'da yapılan bir anket araştırmasında arıcıların tamamının varroa zararlısını tanıdığı, \%31,46'sının yavru çürüklüklerini tanıdığı belirlenmiştir (Kutlu ve ark., 2016). Arıcıların tamamına yakınının varroayı tanıdıkları fakat yeterli mücadeleyi etkin şekilde yapamadıkları, görülmektedir. Arı hastalıklarının tanınmaması, koruma ve mücadele yöntemlerinin bilinçli olarak yapılmaması, gerekli önlemlerin zamanında alınmaması bu hastalıkların arılıklar 


\section{ARAŞTIRMA MAKALESI / RESEARCH ARTICLE}

arasında hatta ülke genelinde hızla yayılmasına neden olmakta ve arıcılığı tehdit eder boyuta ulaşmaktadır. Ancak asıl teşhis laboratuvar koşullarında sağlıklı ve doğru bir şekilde yapılabilmektedir. Bu nedenle arıcı herhangi bir hastalıktan şüphelendiğinde en yakın laboratuara teşhis için numune göndermelidir. Böylece hastalık kaynaklı ekonomik kayıplar minimuma indirilebilir.

Arıcıların \%100'ü varroa, \%77,5’i yavru çürüklüğü, $\% 83,75$ 'i kireç hastalığı, \%2,5 taş hastalığına sıklıkla rastladıklarını belirtmişlerdir. Yapılan bir çalışmada kovan kayıp sebepleri olarak arıcıların \%34'ü yaslı,zayıf kovan ve kraliçeyi, \%26'sı Varroosis'i, \%20'si aşırı soğuk ve rutubeti, \%12'si açlıgı, \%4'ü kireç hastalıgını, \%2'si petek güvesini ve \%2'si zirai ilaçları göstermişlerdir (Aydın ve ark., 2003). Ülke genelinde yapılan bir çalışmada, arıcıların \%98,20 oranda varroa parazitini ve $\% 75,70$ oranında Amerikan yavru çürüklüğünü tanıdıkları belirlenmiştir (Kaftanoğlu, ve ark., 1995). Arı hastalıklarının arıcı tarafından takip edilmesi ve ilgili laboratuvara numune göndermesi oldukça önemlidir. Hastalığı tanıyamama ve yanlış teşhis ciddi ekonomik kayıplara sebep olur.

Arıcılar kayıplarının \%80'inin hastalıklar, \%12,5'inin zirai ilaç ve \%7,5'inin açlıktan kaynaklandığını belirtmişlerdir. Yapılan bir anket çalışmasında zirai ilaçtan kayıpların \%61 olarak tespit edildiği bildirilmiştir (Çakmak ve ark., 2003). Bu oranın yüksek olma sebebi muhtemelen anket çalışmasının zirai ilaç mücadele dönemine denk gelmesinden kaynaklanmaktadır. Arıcının kayıp nedenleri doğru bir şekilde belirlemesi ve buna yönelik önlem alması ekonomik ve koloni kayıplarını önemli derecede önler.

Arıcıların \%82,5'i antibiyotik kullandığını, \%11,25’i ise kullanmadığını belirtmiştir. Yapılan bir anket çalışmasında arıcılar yavru çürüklüğü için apimycine $(\% 43,59)$, perizin $(\% 38,46)$ ve tyramisine $(\% 5,13)$ kullandığını bildirmişlerdir (Kekeçoğlu ve ark., 2013). Tunceli ilinde yapılan bir çalışmada yavru çürüklüklerini önlemek için Neoteramisin ve Teramisin (\%68), apimyesine (\%27) oranında kullandıkları bildirilmiştir (Yerlikaya ve Şahinler, 2007).

Arıcıların bilinçsiz ilaç kullandığı bu çalışmalardan da görülmektedir. Yurt dışında arı hastalıklarında antibiyotik kullanımı yasaktır. İlaç arı ürünlerinde kalıntı bırakmaktadır. Burada arıcılar bilinçsiz olarak farklı ilaçlar, insan ve hayvan sağlığında kullanılan ilaçları kullanabilmekte bu da kalıntı problemi nedeniyle insan sağlığı açısından ciddi problemler oluşturmaktadır. Hastalıklarda antibiyotik kullanılması etkeni baskılamakta daha sonra daha şiddetli olarak ortaya çıkmasına neden olmaktadır. Ayrıca antibiyotik kullanımı sonucu kovanda mantar hastalıkları ortaya çıkmaktadır. $\mathrm{Bu}$ nedenle antibiyotik kullanılmamalıdır.

Güney Marmara bölgesi arıcılık için oldukça uygun bir bölgedir. Ancak koloni sayısına göre elde edilen bal verimi yeterli değildir. Yapılan anket çalışmaları ile arıcıların problemleri, destek istedikleri alanlar, yapılan hatalar, hastalıkları tanımaları konusundaki tecrübeleri, kontrol ve mücadele yöntemleri belirlenerek bu alanlarda çalışmalar, toplantılar, eğitim ve sertifika programları yapılarak arıcılar doğru yönlendirilebilir. Sorunları için ilgili kuruluşlarla iletişime geçilebilir. Bu nedenle anket çalışmalarının en az yılda bir kez tekrarlanması doğru olacaktır.

\section{KAYNAKLAR}

Aydın, L., Çakmak, İ., Güleğen, E. ve Korkut, M., (2003). Güney Marmara Bölgesi'nde arı hastalık ve zararlıları anket sonuçları. Uludağ Arıcılık Dergisi, 3(1):38-41.

Çakmak, İ., Aydın, L., Seven, S., Korkut, M .(2003). Güney Marmara Bölgesi'nde arıcılık anket sonuçları. Uludag Arıcılık Dergisi, 3: 31-36.

Demen, H. (2015). Diyarbakır ilinde arıcılığın yapısı ve sorunların belirlenmesi üzerine bir araştırma. Yüksek Lisans tezi. Adnan Menderes Üniversitesi, Fen Bilimleri Enstitüsü, Aydın

Erkan, E., Aşkın, Y., 2001. Van İli Bahçesaray İlçesi'nde Arıcılığın Yapısı ve Arıcılık Faaliyetleri. Y.Y.Ü. Ziraat Fakültesi Tarım Bilimleri Dergisi, 11(1):19-28.

Kaftanoglu, O., Kumova, U., Yeninar, H., Özkök, D.(1995). Türkiye'de Balarısı (Apis mellifera L.) Hastalıklarının Dağılımı, Koloniler Üzerine Etkileri ve Entegre Kontrol Yöntemlerinin Uygulanması. Türkiye Bilimsel ve Teknik Araştırma Kurumu Veterinerlik ve Hayvancılık Araştırma Grubu Proje No: VHAG-925, Kesin Sonuç Raporu, Ankara.

Kekeçoğlu, M., Rasgele, P., G. (2013). Düzce ili yığılca ilçesindeki arıcılık faaliyetleri üzerine bir çalışma. Uludağ Arıcılık Dergisi, 13 (1): 23-32. 


\section{ARAŞTIRMA MAKALESI / RESEARCH ARTICLE}

Kekeçoğlu, M., Rasgele, P.,G., Acar, F., Kaya, S., T. (2013). Düzce ilinde bulunan arıcılık işletmelerinde görülen koloni kayıplarının, bal arısı hastalık ve zararlılarının ve mücadele yöntemlerinin araştırılması Iğdır Üniversitesi Fen Bilimleri Enstitüsü Dergisi, 3(3):99-108.

Kutlu, M.A. (2014). Gaziantep İli Arıcılık Düzeyinin Saptanması, Sorunları ve Çözüm Yolları. Türk Tarım ve Doğa Bilimleri Dergisi, 1(4): 481-484.

Kutlu, M.A., Özdemir, F.A., Kılıç, Ö. (2016). Hizan İlçesindeki (Bitlis) Aricilik Faaliyetleri Üzerine Bir Araştırma. Mustafa Kemal Üniversitesi Ziraat Fakültesi Dergisi. 21(2):197-206.

Sezgin, A., Kara, M.(2011). Arıcılıkta verim artışı üzerinde etkili olan faktörlerin belirlenmesine yönelik bir araştırma: TRA2 bölgesi örneği. Harran Üniversitesi Ziraat Fakültesi Dergisi, 15: 31-38.

Soysal, M.İ., Gürcan,E.K. (2005).Tekirdağ ili arı yetiştiriciliği üzerine bir araştırma. Tekirdağ Namık Kemal Üniversitesi Ziraat Fakültesi Dergisi. 2: 161-165.

Şahinler, N., Gül, A. (2003). Hatay ilinde arıcılığın yapısal analizi, sorunları ve çözüm önerileri. Mustafa Kemal Üniversitesi Ziraat Fakültesi Dergisi, 8: 105-118.

Tutkun, E., Boşgelmez, A., (2003). Bal Arısı Zararlıları ve Hastalıkları Teşhis ve Tedavi Yöntemleri, Bizim Büro Basımevi, Ankara.

Özbilgin, N., Alataş, İ., Balkan, C., Öztürk, A.İ., Karaca, Ü.(1999). Ege Bölgesi Arıcılık Faaliyetlerinin Teknik ve Ekonomik Başlıca Karakteristiklerinin Belirlenmesi. Ege Tarımsal Araştırma Enstitüsü, Anadolu Dergisi, 9: 149170.

Üçeş, E., Erişir, Z. (2016). Erzincan İli Arıcılığının Sosyo-Ekonomik Yapısı. Fırat Üniversitesi Sağlık Bilimleri Veteriner Dergisi.30 (1): 33 38.

Yerlikaya, H.,R., Şahinler, N. (2007) Tunceli ili Pülümür ilçesinde arıcılığın yapısı, problemleri ve çözüm yolları üzerine bir araştırma, 5.Ulusal Zootekni Bilim Kongresi, YYÜ Ziraat Fak.Van.

Yılmaz, H. (1999). Edirne İli ve Çevresinde Arıcılığın Genel Yapısı, Sorunları ve Çözüm Yolları Üzerine Bir Araştırma. Yüksek Lisans
Tezi, Tekirdağ: Trakya Üniversitesi, Fen Bilimleri Enstitüsü.

\section{EXTENDED ABSTRACT}

Turkey has $20 \%$ of the world's bee breeds. The geography, climatic conditions and honey flora of flora which are the main factors in beekeeping and honey production are suitable. It is a great natural wealth that $75 \%$ of the honey plant species and varieties available in the world are found in Turkey. Turkey has a great beekeeping potential in terms of its rich flora, favorable ecology, colony presence and genetic variation in bee populations. Despite all these favorable conditions, honey production and export are not at desired level. One of the most important reasons for this is the lack of adequate and accurate information about bee diseases and pests, the timekeeping and control of the disease is not done in a timely and accurate manner. Errors in diagnosing diseases and unconscious drug use are also very important. Unnecessary and incorrect drug use threatens both bee and human health seriously.

If the problems in the beekeeping sector in Turkey are identified and necessary precautions are taken, our beekeeping will take its place in the world. For this, it is enough recognition of our beekeepers and beekeeping activities at regional and local level. In order to provide this, questionnaires should be done to determine the problems and a road map should be determined for the solution of the problems.There are a number of questionnaire studies on beekeeping in our country. Determination of the solutions of the problems by further duplication of these studies is very important both in showing the regional situation and in achieving the result.

In this study, a survey was conducted with 80 beekeepers to determine general characteristics of beekeeping and beekeepers in South Marmara Region. Surveys were conducted with the beekeepers of Bursa, Bilecik, Çanakkale, Yalova and Balikesir in Southern Marmara Region.

It was determined that $28.75 \%$ of the beekeepers were between $20-40$ years old and $71.25 \%$ were over 40 years old. It was learned that $33.75 \%$ of the beekeepers had primary school, $28.75 \%$ had middle school, $26.25 \%$ had high school and $11.25 \%$ had university education. According to the survey, it was determined that $27.5 \%$ of them were 


\section{ARAŞTIRMA MAKALESI / RESEARCH ARTICLE}

beekeepers for $0-5$ years, $31.25 \%$ for $5-10$ years and $41.25 \%$ for 10 years. They said that $6.25 \%$ of the beekeepers were the main profession and $83.75 \%$ were the extra income and hobby. The number of hives between $1-10$ is $40 \%$, between 10 50 is $27.5 \%$, between $50-100$ is $8.75 \%, 100$ is over and $23.75 \%$ is over. $81.25 \%$ of the beekeepers were fixed, $18.75 \%$ were reported to be traveler beekeepers. $100 \%$ of the beekeepers stated that they produced honey, $77.5 \%$ pollen, $31.25 \%$ propolis and $25 \%$ royal jelly. While $83.75 \%$ of the beekeepers were members of a beekeeping association or association, $16.25 \%$ were not members. $80 \%$ of the losses are caused by diseases, $12.5 \%$ by pesticides and $7.5 \%$ by hunger.
$82.5 \%$ of the beekeepers stated that they use antibiotics and $11.25 \%$ do not use them.

The southern Marmara region is a very suitable region for beekeeping. However, according to the number of colonies obtained honey is not enough. The surveys that are done and the problems of the beekeepers, the fields they want to support, the mistakes made, the experiences of knowing the diseases, the control and the methods of struggle are determined and the beekeepers can be guided through the works, meetings, training and certificate programs in these areas. Communication with related organizations can be made for their reasons. It will be correct to repeat it at least once a year. 